\title{
Perancangan Aplikasi Pengenalan Tempat Wisata di Jawa Barat Berbasis Multimedia
}

\author{
Desiyanna Lasut \\ Program Studi Sarjana Teknik Informatika \\ STMIK BUDDHI \\ Jl. Imam Bonjol No. 41, Tangerang Banten Indonesia \\ desiyanna_lassut@yahoo.com
}

\author{
Susanto Haryanto \\ Program Studi Sarjana Teknik Informatika \\ STMIK BUDDHI \\ Jl. Imam Bonjol No. 41, Tangerang Banten Indonesia \\ sanada_000@yahoo.com
}

\begin{abstract}
Abstrak - Teknologi telah berkembang pesat sesuai dengan perkembangan jaman dan pemikiran manusia. Pada jaman sekarang ini teknologi telah digunakan bukan hanya untuk memenuhi kebutuhan jasmani maupun komunikasi saja tapi teknologi juga digunakan untuk mencari dan mengetahui tempat wisata terpopuler dan yang menarik. Adapun yang menjadi daya tarik bagi manusia yaitu: adanya keinginan untuk mencari tempat wisata yang sangat sesuai dengan keinginan masing-masing setiap manusia tersebut, namun padatnya manusia dengan aktivitas akan penggunaan teknologi maka membuat mereka cenderung memilih untuk hidup praktis. Hal ini menjadikan banyak yang belum mengetahui tempat wisata apa aja yang menarik dan unik di Jawa Barat. Jawa Barat merupakan salah satu Propinsi yang kaya akan tempat wisata dengan keindahan dan keunikannya. Banyak tempat wisata di Jawa Barat yang jauh informasi nya dari manusia dan minim nya informasi yang lebih lengkap tentang tempat wisata di Jawa Barat. Banyak manusia hanya tahu tempat wisata tersebut tapi tidak tahu asal mula tempat wisata tersebut beserta keunikan yang ada di dalam tempat wisata tersebut. Aplikasi ini dilengkapi dengan animasi, teori, dan pendapat - pendapat terkemuka, agar pengguna dapat memahami maksud dan isi informasi yang disampaikan dalam bentuk aplikasi dengan mudah dan menarik. Rancangan aplikasi ini menggunakan storyboard yang terdiri dari halaman intro, user id, menu utama dan menu jawa barat, hiburan, evaluasi, dan 16 daerah yang terdapat pada dalam sebuah peta jawa barat masing-masing daerah berisi tempat wisata yang akan menampilkan video, gambar, penjelasan materi belajar yang dibuat dengan menggunakan Adobe Flash CS5 sebagai software utamanya dan codiing sebagai pembangun aplikasi [5]. Pengujian sistem dengan menggunakan metode white box dengan menganalisa alur aplikasi dan black box dengan menguji semua tombol pada aplikasi serta menggunakan kuisioner untuk mengetahui pendapat pengguna mengenai aplikasi yang telah dibuat. Berdasarkan hasil penelitian pembelajaran ini dapat meningkatkan pemahaman dan telah mempermudah pengguna dalam mendapatkan informasi tentang tempat wisata di jawa barat, mengetahui tempat wisata yang menarik di Jawa Barat, dan mempunyai standarisasi informasi yang diketahui dari informasi yang diterima, sehingga banyak orang dapat memutuskan tempat wisata yang cocok.
\end{abstract}

Kata Kunci -Perancangan; Aplikasi; Multimedia; Tempat Wisata; Jawa Barat; Edukasi
Pengenalan;

\section{PENDAHULUAN}

Teknologi telah berkembang pesat sesuai dengan perkembangan jaman dan pemikiran manusia. Bahkan lebih dari satu teknologi telah diciptakan untuk memenuhi kebutuhan manusia dan membantu manusia untuk melakukan segala aktivitas, baik yang disadari maupun yang tidak disadari secara langsung [2][3].

Pada jaman sekarang ini teknologi telah digunakan bukan hanya untuk memenuhi kebutuhan jasmani maupun komunikasi saja tapi teknologi juga digunakan untuk mencari dan mengetahui tempat wisata terpopuler dan yang menarik. Adapun yang menjadi daya tarik bagi manusia yaitu: adanya keinginan untuk mencari tempat wisata yang sangat sesuai dengan keinginan masing-masing setiap manusia tersebut. Dan yang tidak kalah pentingnya adalah tempat wisata yang menarik dan unik untuk di kunjungi.

Seiring dengan perkembangan jaman yang semakin modern ini, banyak sekali orang lebih selektif untuk memilih tempat wisata yang diinginkan, bagaimana tempat wisata tersebut dan bagaimanakah keunikan tempat wisata masing - masing, namun hal ini menjadikan banyak manusia mencari tahu dengan menggunakan segala teknologi yang ada, namun padatnya manusia dengan aktivitas akan penggunaan teknologi maka membuat mereka cenderung memilih untuk hidup praktis. Hal ini menjadikan banyak yang belum mengetahui tempat wisata apa aja yang menarik dan unik di Jawa Barat. Jawa Barat merupakan salah satu Propinsi yang kaya akan tempat wisata dengan keindahan dan keunikannya.

Banyak tempat wisata di Jawa Barat yang jauh informasi nya dari manusia dan minim nya informasi yang lebih lengkap tentang tempat wisata di Jawa Barat. Banyak manusia hanya tahu tempat wisata tersebut tapi tidak tahu asal mula tempat wisata tersebut beserta keunikan yang ada di dalam tempat wisata tersebut [1].

\section{PERANCANGAN SISTEM}

\section{A. Analisa Kebutuhan Sistem}

Untuk memenuhi kebutuhan pengguna maka peneliti perlu mengadakan survey kepada beberapa orang yang paham 
dalam pembuatan aplikasi pembelajaran dan atau yang paham tentang tempat wisata di Jawa Barat. Dimana jawaban responden merupakan pernyataan apa saja yang diperlukan dalam pembuatan aplikasi yang dibuat oleh peneliti.

Dari survey dilakukan kepada 20 (dua puluh) orang yang paham tentang aplikasi pembelajaran dan atau orang yang paham tentang tempat wisata. Peneliti mendapatkan beberapa pernyataan dari responden yang dapat dijadikan sebagai referensi dalam pembuatan aplikasi ini. Berikut adalah uraian dari hasil survey yang dilakukan:

Tabel 1. Tabel Analisa Kebutuhan Pemakai

\begin{tabular}{|c|c|c|}
\hline No. & Kebutuhan Pemakai & Keterangan \\
\hline 1 & $\begin{array}{l}\text { Aplikasi dapat dimengerti dengan mudah } \\
\text { pemakaiannya }\end{array}$ & $\sqrt{ }$ \\
\hline 2 & $\begin{array}{lllll}\text { Memiliki interface } & \text { yang menarik dan } \\
\text { interaktif }\end{array}$ & $\sqrt{ }$ \\
\hline 3 & Terdapat animasi yang menarik & $\sqrt{ }$ \\
\hline 4 & Adanya suara / musik latar yang mengiringi & $\sqrt{ }$ \\
\hline 5 & Adanya video & $\sqrt{ }$ \\
\hline 6 & Adanya gambar / tampilan 3 dimensi & $\mathrm{x}$ \\
\hline 7 & Adanya evaluasi & $\sqrt{ }$ \\
\hline 8 & Ada pengaturan suara / volume & $\mathrm{x}$ \\
\hline 9 & Adanya soal uji kompetensinya & $\sqrt{ }$ \\
\hline 10 & Dapat ditampilkan pada web & $\mathrm{x}$ \\
\hline 11 & Memberikan efek sound pada setiap button & $\sqrt{ }$ \\
\hline 12 & Menampilkan secara fullscreen & $\sqrt{ }$ \\
\hline 13 & Ada login user & $\sqrt{ }$ \\
\hline 14 & Ada maskot aplikasi & $\sqrt{ }$ \\
\hline 15 & Warna yang digunakan ramah dimata & $\sqrt{ }$ \\
\hline 16 & Ada nya petunjuk penggunaan & $\mathrm{x}$ \\
\hline 17 & User Friendly & $\sqrt{ }$ \\
\hline 18 & Ada penjelasan tentang topik & $\sqrt{ }$ \\
\hline 19 & $\begin{array}{l}\text { Dilengkapi dengan penjelasan dasar tentang } \\
\text { Jawa Barat }\end{array}$ & $\sqrt{ }$ \\
\hline 20 & $\begin{array}{l}\text { Dilengkapi penjelasan tentang masing-masing } \\
\text { tempat wisata di Jawa Barat }\end{array}$ & $\sqrt{ }$ \\
\hline 21 & Memaparkan kata - kata yang sopan & $\sqrt{ }$ \\
\hline
\end{tabular}

\section{B. Perancangan User Interface}

Perancangan dari sistem berdasarkan tema penelitian ini menghasilkan beberapa halaman yang serupa dengan berisikan materi yang berbeda antara satu pembahasan dengan pembahasan lainnya [4]. Adapun tampilan - tampilan program adalah sebagai berikut:

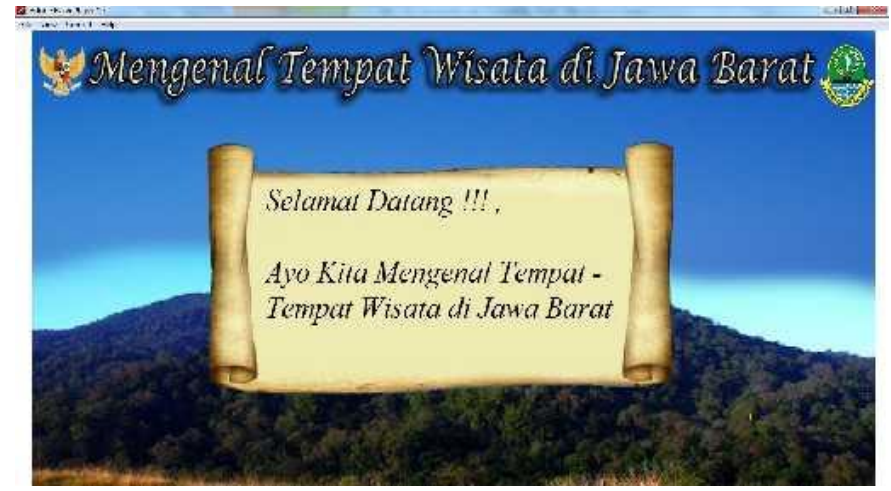

Gambar 1. Intro Aplikasi

Pada Gambar 1 terdapat lambang garuda sebelah kiri, dari sisi kanan maskot Jawa Barat dan disertai ucapan selamat datang beserta judul dari aplikasi, dan secara langsung akan mengarahkan pengguna ke user ID aplikasi.

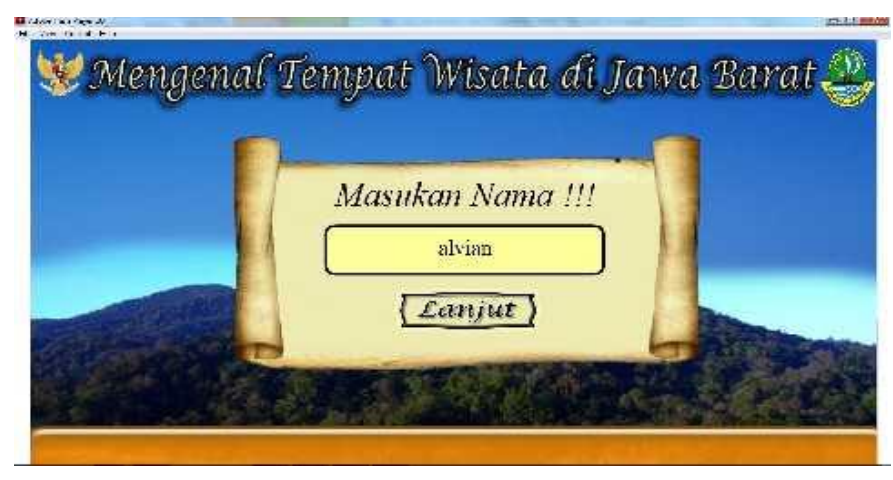

Gambar 2. User ID

Pada Gambar 2 wajib untuk mengisi nama pengguna, terdapat juga background sound yang akan mengiringi aplikasi ini. Setelah mengisi user ID pengguna bisa mengklik lanjut untuk ke menu utama / home.

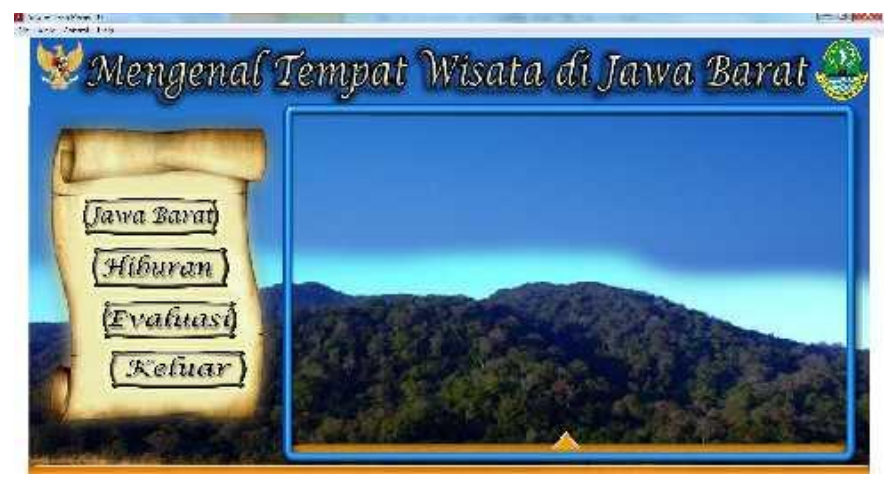

Gambar 3. Menu Utama

Pada Gambar 3 terdapat tombol Jawa Barat, hiburan, evaluasi, keluar, dan tombol segitiga dengan masing - masing fungsi yang berbeda - beda beserta background sound 


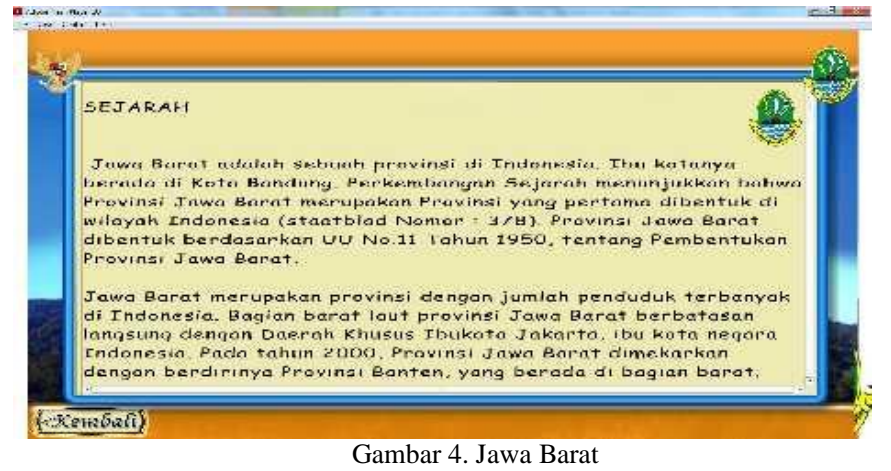

Pada Gambar 4 berisi penjelasan tentang Jawa Barat secara ringkas. Menu pilihan ini terdapat tombol kembali untuk mengembalikan ke menu utama.

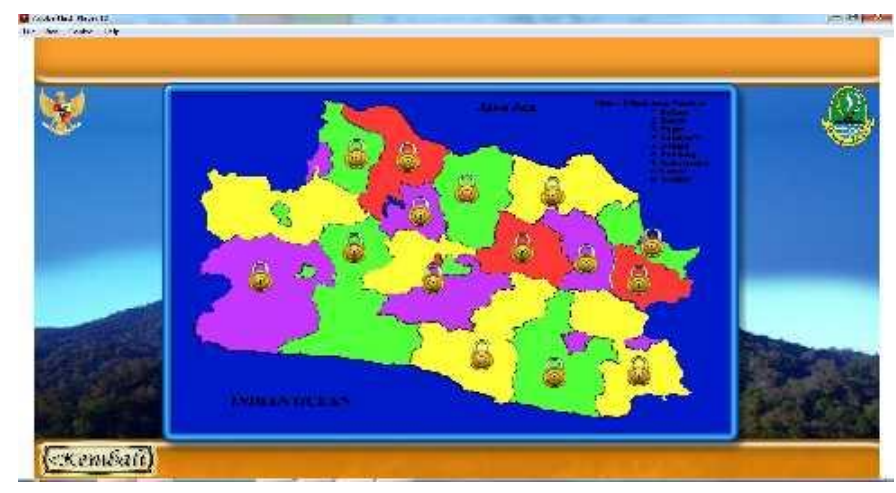

Gambar 5. Hiburan

Pada Gambar 5 menampilkan uji kompetensi / soal untuk seberapa jauh anda mengenal masing-masing tempat wisata, terdiri dari 16 daerah dan daerah pertama adalah bogor untuk memulai soal nya, jika gagal pada daerah pertama tidak bisa melangkah ke daerah tempat wisata selanjutnya. Soal tempat wisata ini berisi 10 soal, jika gagal menyelesaikan 10 soal pada daerah pertama tidak bisa melangkah ke daerah tempat wisata selanjut nya, minimal benar 6 baru bisa melangkah selanjutnya.

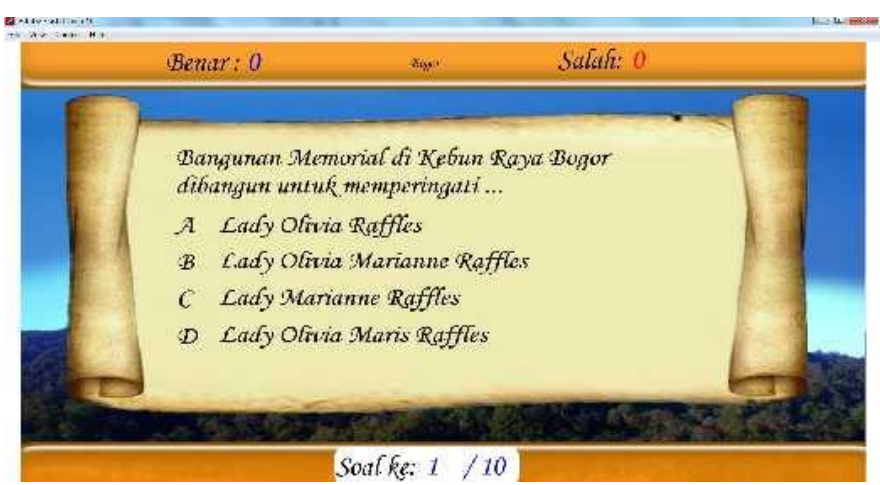

Gambar 6. Soal Hiburan

Pada Gambar 6 terdapat soal beserta pilihan ganda, terdapat 10 soal masing-masing tempat wisata, jika berhasil akan next ke tempat wisata selanjut-nya.

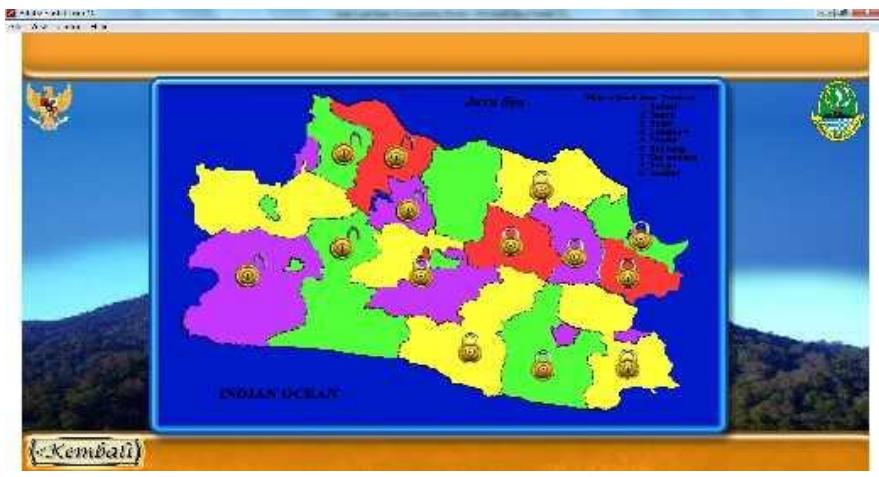

Gambar 7. Daerah Terbuka

Pada Gambar 7 akan terbuka, jika berhasil menyelesaikan soal daerah pertama dan akan menuju ke daerah selanjutnya.

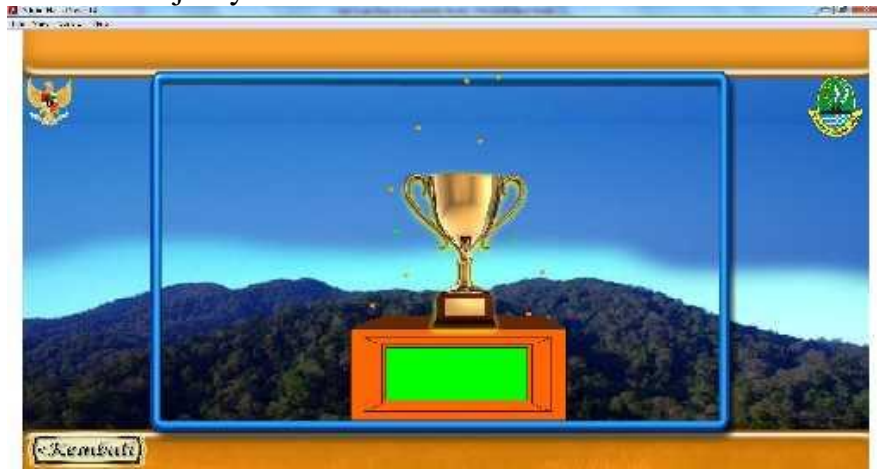

Gambar 8. Piala

Pada G a mbar 8 menampilkan gambar piala beserta animasi jika telah menyelesaikan seluruh daerah. Tombol kembali akan menampilkan kembali ke menu utama.

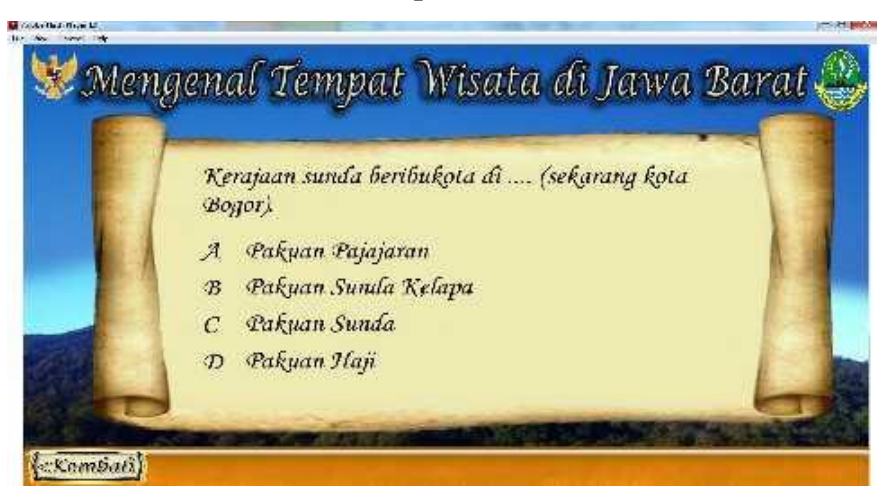

Gambar 9. Evaluasi

Pada Gambar 9 terdapat soal yang akan menampilkan 10 soal yang dipilih acak berdasarkan keseluruhan dan berisi nilai / score. 


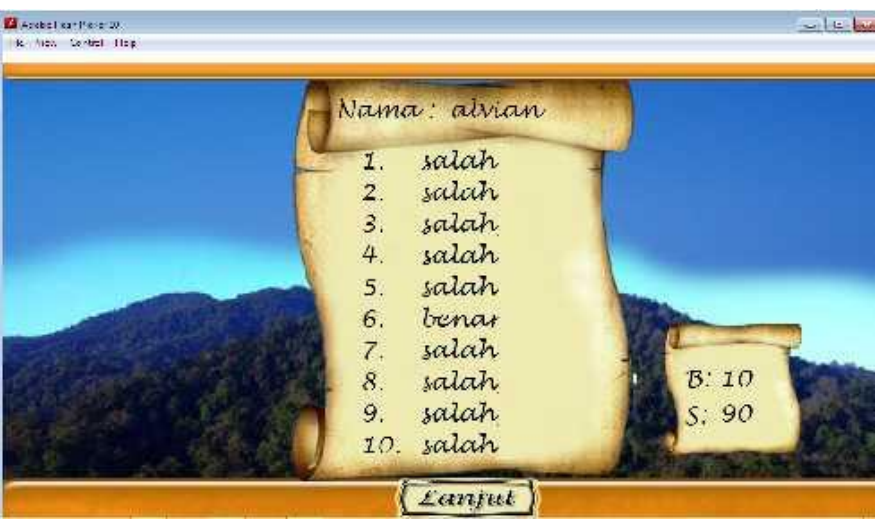

Gambar 10. Score Evaluasi

Pada Gambar 10 menampilkan score total keseluruhan soal yang telah di jawab. Tombol lanjut untuk menuju pada tampilan Stock User ID.

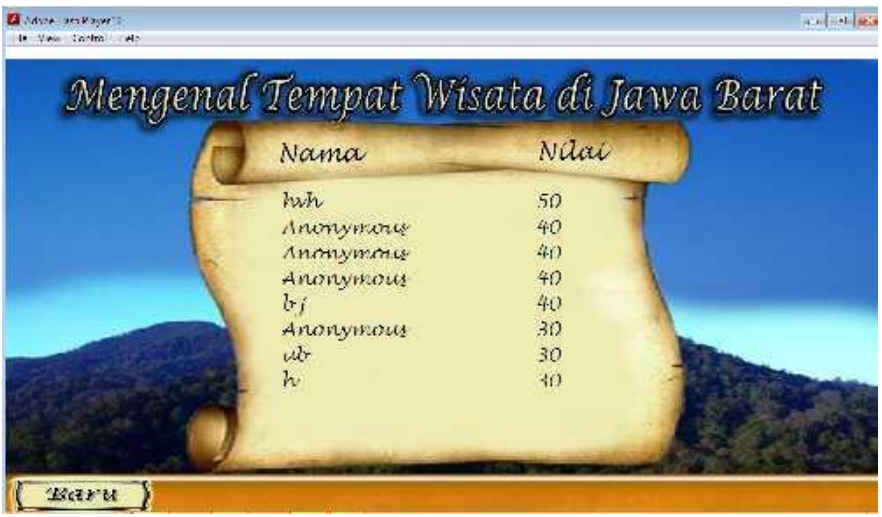

Gambar 11. Score User ID

Pada gambar 11 menampilkan user ID yang telah menjalankan Evaluasi beserta score / nilai masing-masing. Tombol baru untuk masuk ke tampilan User ID untuk mengulang membuat user ID.

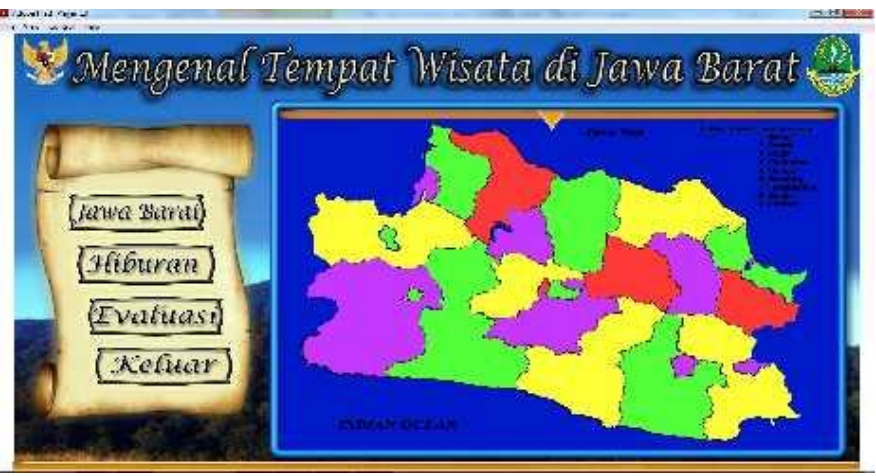

Gambar 12. Peta

Pada Gambar 12 terdapat peta ketika klik tombol segitiga maka muncul gambar peta yang dapat di klik setiap daerah nya, dan 4 tombol aktif sebelah kiri gambar peta.

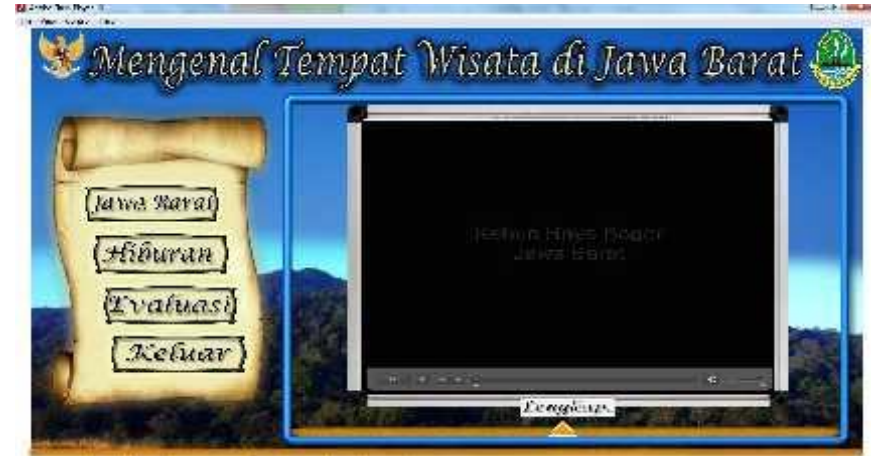

Gambar 13. Video Tempat Wisata

Pada Gambar 13 terdapat video tentang tempat wisata dan 4 tombol aktif di sebelah kiri layar, dan tombol lengkap untuk mengetahui tempat wisata lebih dalam lagi

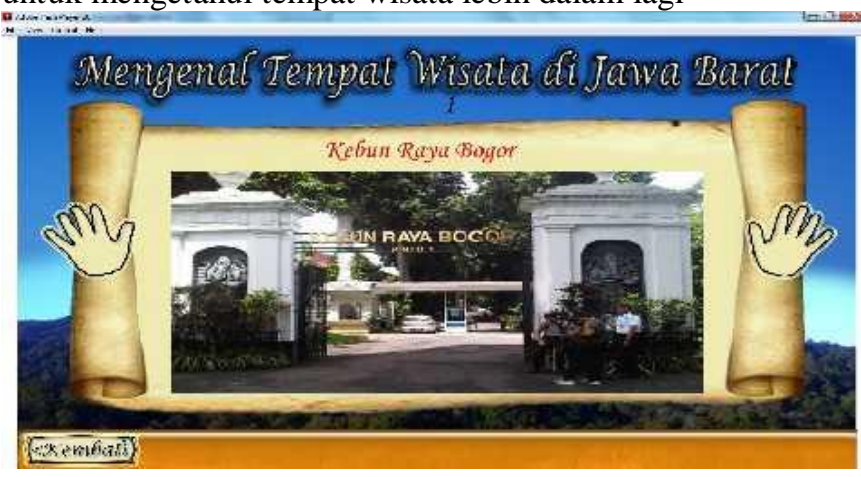

Gambar 14. Tempat Wisata

Pada Gambar 14 terdapat gambar tempat wisata, gambar kedua tangan kiri dan kanan, tombol kiri berfungsi untuk kembali pada penjelasan sebelumnya, tombol kanan untuk penjelasan selanjutnya dan tombol kembali untuk ke menu utama / home.

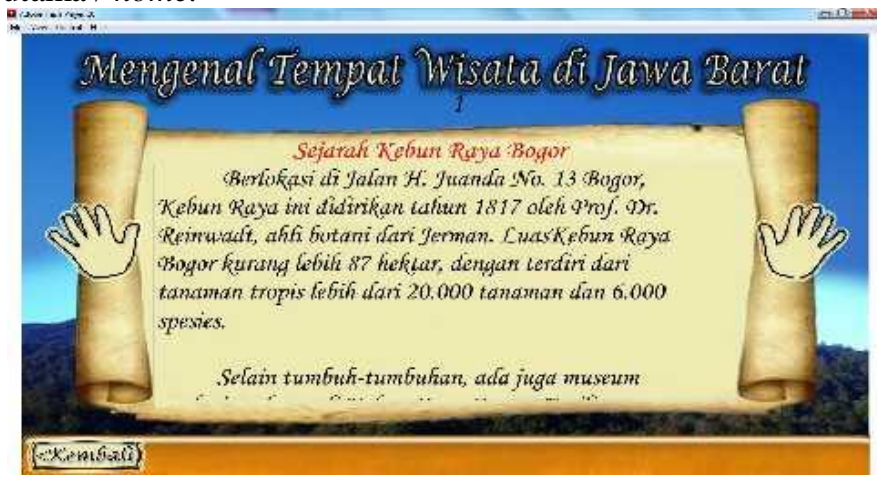

Gambar 15. Penjelasan Tempat Wisata

Pada Gambar 15 terdapat penjelasan tentang tempat wisata mulai dari sejarah, fasilitas, rute wisata, dan hotel terdekat tempat wisata, tombol kiri untuk kembali ke penjelasan sebelumnya, tombol kanan untuk penjelasan selanjut nya dan tombol kembali untuk ke menu utama / home. 


\section{PEMBAHASAN SISTEM}

A. Diagram Alir Aplikasi

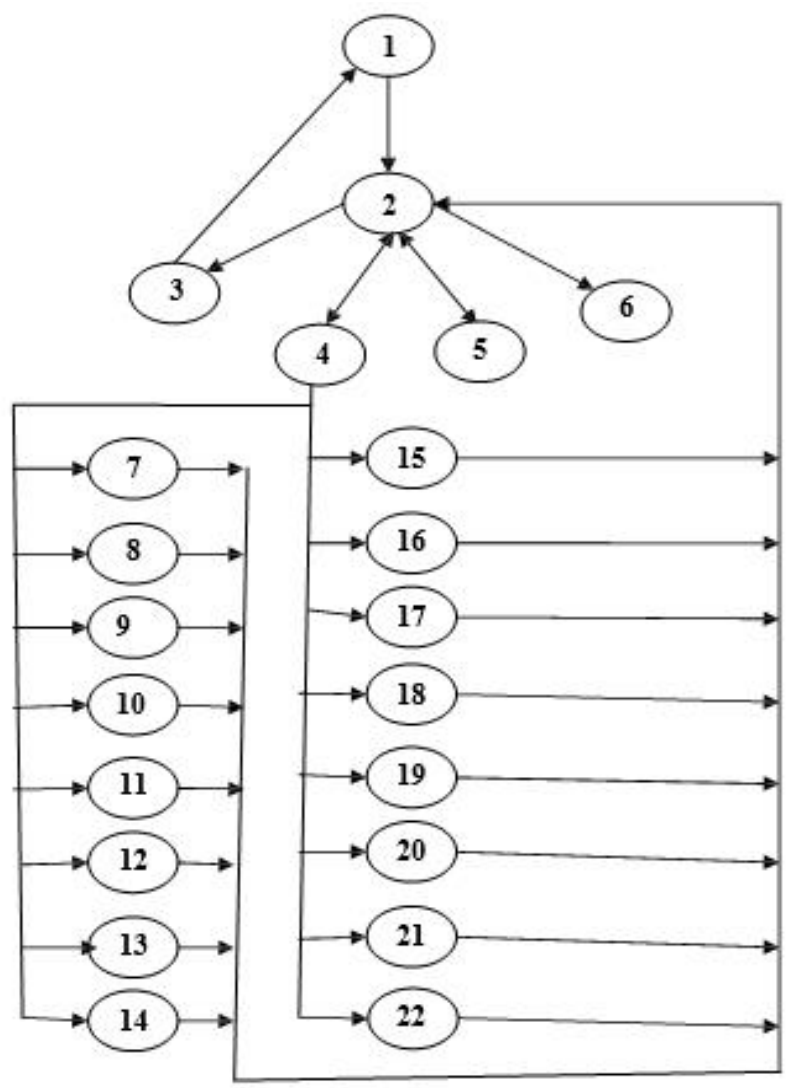

Gambar 16 Diagram Alir Aplikasi

Path yang dapat dibentuk sebagai berikut:

Path 1: $1-2-6$

Path 2: 2-3-1-6

Path 3: 2-4-2-6

Path 4: $2-4-7-4-2-6$

Path 5: 2-4-8-4-2-6

Path 6: $2-4-9-4-2-6$

Path 7: 2-4-10-4-2-6

Path 8: 2-4-11-4-2-6

Path 9: 2-4-12-4-2-6

Path 10: 2-4-13-4-2-6

Path 11: 2-4-14-4-2-6

Path 12: 2-4-15-4-2-6

Path 13: 2-4-16-4-2-6

Path 14: 2-4-17-4-2-6

Path 15: 2-4-18-4-2-6

Path 16: 2-4-19-4-2-6

Path 17: 2-4-20-4-2-6

Path 18: 2-4-21-4-2-6

Path 19: 2-4-22-4-2-6

Path 20: 2-5-2-6

Region yang dapat dibentuk sebanyak dua puluh (20), selanjutnya akan di uji dengan menggunakan rumus Cyclomatic Complexcity.
Jurnal SISFOKOM, Volume 05, Nomor 01, Maret 2016

$$
\begin{aligned}
\mathrm{V}(\mathrm{G}) & =\mathrm{E}-\mathrm{N}+2 \\
& =40-22+2 \\
& =20
\end{aligned}
$$

Dari region yang didapat menggunakan diagram alir dan rumus menunjukan jumlah yang sama, yang artinya sistem sudah berjalan dengan benar. Selanjutnya akan diteruskan dengan pengujian blackbox.

\section{B. Pengujian Blackbox}

Pengujian black box akan menguji apakah tombol-tombol pada tiap Scene bekerja dengan baik atau tidak. Berikut hasil

\begin{tabular}{|c|c|c|c|}
\hline $\begin{array}{l}\text { Uji } \\
\text { Coba/S } \\
\text { cene }\end{array}$ & Uraian & Hasil yang diharapkan & $\begin{array}{l}\text { Hasil } \\
\text { sebenarnya }\end{array}$ \\
\hline 1 & $\begin{array}{l}\text { Muncul animasi } \\
\text { intro pembuka, } \\
\text { tampilan user } \\
\text { ID }\end{array}$ & Masuk ke menu utama & Sesuai \\
\hline 2 & $\begin{array}{l}\text { Muncul } \\
\text { tampilan menu } \\
\text { utama }\end{array}$ & $\begin{array}{l}\text { Muncul tombol jawa } \\
\text { barat, hiburan, evaluasi, } \\
\text { keluar, dan tombol scroll }\end{array}$ & Sesuai \\
\hline 3 & $\begin{array}{l}\text { Tombol } \\
\text { evaluasi }\end{array}$ & $\begin{array}{l}\text { Masuk ke halaman } \\
\text { evaluasi yang berisi } \\
\text { rangkuman soal semua } \\
\text { daerah tempat wisata }\end{array}$ & Sesuai \\
\hline 4 & Tombol hiburan & $\begin{array}{l}\text { Masuk ke halaman hiburan } \\
\text { yang berisi soal - soal } \\
\text { setiap daerah tempat } \\
\text { wisata }\end{array}$ & Sesuai \\
\hline 5 & $\begin{array}{l}\text { Tombol jawa } \\
\text { barat }\end{array}$ & $\begin{array}{l}\text { Masuk ke halaman jawa } \\
\text { barat yang berisi } \\
\text { penjelasan singkat tentang } \\
\text { jawa barat. }\end{array}$ & Sesuai \\
\hline 6 & Tombol keluar & $\begin{array}{l}\text { Masuk ke menu exit dan } \\
\text { keluar dari program } \\
\text { dengan animasi penutup }\end{array}$ & Sesuai \\
\hline 7 & Tombol bogor & $\begin{array}{l}\text { Masuk ke tampilan tempat } \\
\text { wisata di bogor berisi } \\
\text { video, gambar, dan } \\
\text { penjelasan. }\end{array}$ & Sesuai \\
\hline 8 & Tombol bekasi & $\begin{array}{l}\text { Masuk ke tampilan tempat } \\
\text { wisata di bekasi berisi } \\
\text { video, gambar, dan } \\
\text { penjelasan. }\end{array}$ & Sesuai \\
\hline 9 & $\begin{array}{l}\text { Tombol } \\
\text { karawang }\end{array}$ & $\begin{array}{l}\text { Masuk ke tampilan tempat } \\
\text { wisata di karawang berisi } \\
\text { video, gambar, dan } \\
\text { penjelasan. }\end{array}$ & Sesuai \\
\hline 10 & $\begin{array}{l}\text { Tombol } \\
\text { sukabumi }\end{array}$ & $\begin{array}{l}\text { Masuk ke tampilan tempat } \\
\text { wisata di sukabumi berisi } \\
\text { video, gambar, dan } \\
\text { penjelasan }\end{array}$ & Sesuai \\
\hline 11 & Tombol cianjur & $\begin{array}{l}\text { Masuk ke tampilan tempat } \\
\text { wisata di cianjur berisi } \\
\text { video, gambar, dan } \\
\text { penjelasan. }\end{array}$ & Sesuai \\
\hline 12 & $\begin{array}{l}\text { Tombol } \\
\text { purwakarta }\end{array}$ & $\begin{array}{l}\text { Masuk ke tampilan tempat } \\
\text { wisata di purwakarta berisi } \\
\text { video, gambar, dan } \\
\text { penjelasan. }\end{array}$ & Sesuai \\
\hline 13 & Tombol subang & $\begin{array}{l}\text { Masuk ke tampilan tempat } \\
\text { wisata di subang berisi } \\
\text { video, gambar, dan }\end{array}$ & Sesuai \\
\hline
\end{tabular}
pengujian setiap tombol pada tiap Scene.

Tabel 2 Pengujian Blackbox 


\begin{tabular}{|c|c|c|c|}
\hline & & penjelasan. & \\
\hline 14 & $\begin{array}{l}\text { Tombol } \\
\text { bandung }\end{array}$ & $\begin{array}{l}\text { Masuk ke tampilan tempat } \\
\text { wisata di bandung berisi } \\
\text { video, gambar, dan } \\
\text { penjelasan. }\end{array}$ & Sesuai \\
\hline 15 & $\begin{array}{l}\text { Tombol } \\
\text { indramayu }\end{array}$ & $\begin{array}{l}\text { Masuk ke tampilan tempat } \\
\text { wisata di indramayu berisi } \\
\text { video, gambar, dan } \\
\text { penjelasan }\end{array}$ & Sesuai \\
\hline 16 & $\begin{array}{l}\text { Tombol } \\
\text { sumedang }\end{array}$ & $\begin{array}{l}\text { Masuk ke tampilan tempat } \\
\text { wisata di sumedang berisi } \\
\text { video, gambar, dan } \\
\text { penjelasan. }\end{array}$ & Sesuai \\
\hline 17 & $\begin{array}{l}\text { Tombol } \\
\text { majalengka }\end{array}$ & $\begin{array}{l}\text { Masuk ke tampilan tempat } \\
\text { wisata di majalengka berisi } \\
\text { video, gambar, dan } \\
\text { penjelasan. }\end{array}$ & Sesuai \\
\hline 18 & Tombol garut & $\begin{array}{l}\text { Masuk ke tampilan tempat } \\
\text { wisata di garut berisi } \\
\text { video, gambar, dan } \\
\text { penjelasan. }\end{array}$ & Sesuai \\
\hline 19 & Tombol cirebon & $\begin{array}{l}\text { Masuk ke tampilan tempat } \\
\text { wisata di cirebon berisi } \\
\text { video, gambar, dan } \\
\text { penjelasan. }\end{array}$ & Sesuai \\
\hline 20 & $\begin{array}{l}\text { Tombol } \\
\text { tasikmalaya }\end{array}$ & $\begin{array}{l}\text { Masuk ke tampilan tempat } \\
\text { wisata di tasikmalaya } \\
\text { berisi video, gambar, dan } \\
\text { penjelasan. }\end{array}$ & Sesuai \\
\hline 21 & Tombol ciamis & $\begin{array}{l}\text { Masuk ke tampilan tempat } \\
\text { wisata di ciamis berisi } \\
\text { video, gambar, dan } \\
\text { penjelasan. }\end{array}$ & Sesuai \\
\hline 22 & $\begin{array}{l}\text { Tombol } \\
\text { kuningan }\end{array}$ & $\begin{array}{l}\text { Masuk ke tampilan tempat } \\
\text { wisata di kuningan berisi } \\
\text { video, gambar, dan } \\
\text { penjelasan. }\end{array}$ & Sesuai \\
\hline
\end{tabular}

\section{Hasil Pengolahan Kuesioner}

Tabel 3 Hasil Kuesioner Secara Keseluruhan

\begin{tabular}{|c|c|c|c|c|c|}
\hline \multirow{2}{*}{ No. } & \multirow{2}{*}{ Pertanyaan } & \multicolumn{2}{|l|}{$\mathrm{Ya}$} & \multicolumn{2}{|c|}{ Tidak } \\
\hline & & Jumlah & $\%$ & Jumlah & $\%$ \\
\hline 1 & Pertanyaan 1 & 16 & $90 \%$ & 4 & $10 \%$ \\
\hline 2 & Pertanyaan 2 & 18 & $80 \%$ & 2 & $20 \%$ \\
\hline 3 & Pertanyaan 3 & 16 & $90 \%$ & 4 & $10 \%$ \\
\hline 4 & Pertanyaan 4 & 18 & $70 \%$ & 2 & $30 \%$ \\
\hline 5 & Pertanyaan 5 & 17 & $90 \%$ & 3 & $10 \%$ \\
\hline 6 & Pertanyaan 6 & 19 & $80 \%$ & 1 & $20 \%$ \\
\hline 7 & Pertanyaan 7 & 19 & $60 \%$ & 1 & $40 \%$ \\
\hline 8 & Pertanyaan 8 & 19 & $90 \%$ & 1 & $10 \%$ \\
\hline
\end{tabular}

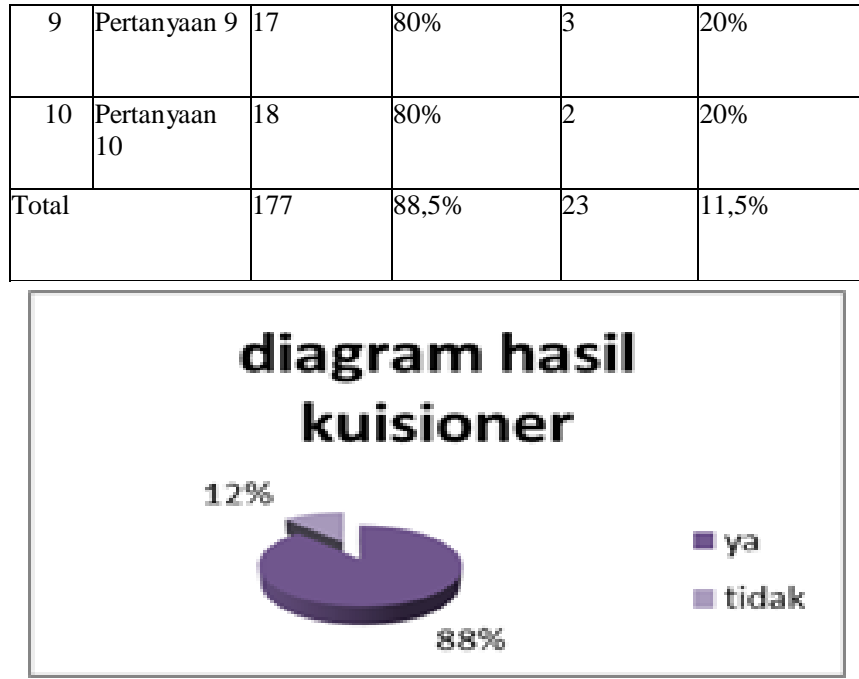

Gambar 17 Diagram Hasil Kuesioner Secara Keseluruhan

Setelah kuisioner dibagikan dan didapat hasil berupa data serta dianalisa maka dapat disimpulkan bahwa aplikasi ini adalah baik. Pengguna dapat mengerti cara penggunaan aplikasi serta memahami informasi yang diberikan karena dilengkapi contoh gambar, video dan animasi yang bervariasi sehingga membantu pengguna mengetahui tempat wisata yang menarik.

\section{PENUTUP}

A. Kesimpulan

Berdasarkan uji coba dan evaluasi yang telah dilakukan maka dapat diambil kesimpulan sebagai berikut:

- Aplikasi yang memaparkan informasi dan pembelajaran ini sudah dapat membantu pengguna untuk mendapatkan informasi tentang tempat wisata di Jawa Barat.

- Berdasarkan hasil kuisioner, pengguna sudah dapat mengetahui, membedakan, dan menentukan tempat wisata yang diinginkan di Jawa Barat dengan menggunakan aplikasi pengenalan tempat wisata di Jawa Barat.

\section{B. Saran}

Berdasarkan analisa yang telah dilakukan maka dapat diusulkan beberapa saran agar aplikasi pembelajaran ini lebih baik lagi, yaitu:

- Menambahkan gambar, video, animasi serta suara agar lebih menarik lagi.

- Menambahkan tempat wisata yang selalu di perbaharui.

- Menambahkan penjelasan permainan sederhana untuk menghibur dan meningkatkan pemahaman tentang tempat wisata. 


\section{DAFTAR PUSTAKA}

[1] Warpani, Suwardjoko P. dan Warpani, Indira P, 2007, Pariwisata Dalam Tata Ruang Wilayah, Bandung: ITB.

[2] Y. Maryono , dan B. Patmi Istiana, 2007, Teknologi Informasi \& komunikasi, Jakarta: Penerbit Yudistira.

[3] Hanif Al Fatta, 2008, Analisis \& Perancangan Sistem Informasi untuk Keunggulan Bersaing Perusahaan \& Organisasi Modern, Yogyakarta: Andi.
Jurnal SISFOKOM, Volume 05, Nomor 01, Maret 2016

[4] Santoso Insap, 2009, Interaksi Manusia dan Komputer, Yogyakarta: Andi.

[5] Soeherman Bonnie, Halim Cipta, 2008, Membuat Sendiri Klip Animasi Multimedia, Jakarta: PT. Elex Media Komputindo. 